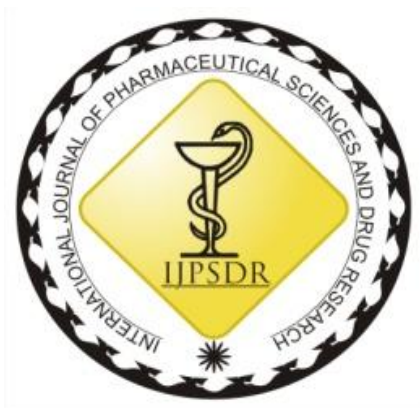

ISSN: 0975-248X

RESEARCH ARTICLE CODEN (USA): IJPSPP

$(\mathrm{cc})$ EY-NG-SA

\title{
Formulation and in vivo Evaluation of Chronomodulated Drug Delivery of Nimodipine
}

\author{
Raghavender Chenna*, Y. Padmanabha Reddy \\ Raghavendra Institute of Pharmaceutical Education and Research, Ananthapuramu, Andhra Pradesh, India
}

Copyright (c) 2019 Raghavender Chenna et al. This is an open access article distributed under the terms of the Creative Commons AttributionNonCommercial-ShareAlike 4.0 International License which allows others to remix, tweak, and build upon the work non-commercially, as long as the author is credited and the new creations are licensed under the identical terms.

\begin{abstract}
Chronotherapy has been emerging as a novel technology in the field of pharmaceutical research. Delivery of drugs with respect to the circadian rhythm has gained greater importance in the diseases such as diabetes, asthma and hypertension in producing maximum therapeutic action. Present study focus on the formulation and evaluation of Nimodipine pulsatile release tablets with the incorporation of Eudragit $\mathrm{pH}$ sensitive polymers used for the chronotherapy of hypertension. Pharmacologically Nimodipine is an anti-hypertensive agent that acts by blocking the L and N-type calcium channels. Evaluation parameters for Nimodipine tablets included friability, drug content, bulk and tapped density, angle of repose and Carr's index and drug release in vitro and in vivo.
\end{abstract}

Keywords: Chronotherapy, circadian variation, hypertension, press coated tablets, pulsatile.

*Corresponding author: Mr. Raghavender Chenna

Address: Raghavendra Institute of Pharmaceutical Education and Research, Ananthapuramu, Andhra Pradesh, India

Tel.: +91-9642053555

E-mail $\bowtie$ : raghupharma02@gmail.com

Relevant conflicts of interest/financial disclosures: The authors declare that the research was conducted in the absence of any commercial or financial relationships that could be construed as a potential conflict of interest.

Received: 21 August, 2019; Revised: 10 October, 2019; Accepted: 27 October, 2019; Published: 30 November, 2019

\section{INTRODUCTION}

Development of chronotherapy as a novel strategy in drug delivery systems altered the therapeutic approach for various serious diseases such as hypertension, congestive heart failure, stroke, cancer, type-2 diabetes, ulcer, asthma, arthritis and hypercholesterolemia. The onset of symptoms for these diseases alters with the day \& night cycle which is considered as a major cause for the evolution of chronopharmacology. Chronopharmacotherapy is based on the circadian rhythms involved in the body through which the drug is released at a pre-determined time that facilitates a beneficial therapeutic effect. ${ }^{[1-3]}$ Drugs with higher first pass effect and drugs that require dosing during the night can be modulated as chronotherapeutic agents which deliver complete release of drug after a delayed time. ${ }^{[4]}$ Chrono modulating system is otherwise called pulsatile or sigmoidal release system which is analogous to biological rhythm. [5] These systems release the drug at the required time and at required concentration at the site of action. ${ }^{[6]}$ Pulsatile systems are beneficial in treating diseases which require a patterned release of drug. ${ }^{[7]}$

Nimodipine a specific calcium channel blocker at L \& N-type calcium channels is used as an antihypertensive agent that causes arteriolar and venal dilatation leading to a fall in the pressure of capillary bed. [8-10] 
Raghavender Chenna et al. / Formulation and in vivo Evaluation of Chronomodulated Drug Delivery...........

Table 1: formulation of Pulsatile Release Tablet of Nimodipine

\begin{tabular}{ccccccccccccccccccc}
\hline $\begin{array}{c}\text { Formulation } \\
\text { ingredients (mg) }\end{array}$ & F1 & F2 & F3 & F4 & F5 & F6 & F7 & F8 & F9 & F10 & F11 & F12 & F13 & F14 & F15 & F16 & F17 & F18 \\
\hline Nimodipine & 30 & 30 & 30 & 30 & 30 & 30 & 30 & 30 & 30 & 30 & 30 & 30 & 30 & 30 & 30 & 30 & 30 & 30 \\
Croscarmellose sodium & 2 & 4 & 6 & 8 & 10 & 12 & - & - & - & - & - & - & - & - & - & - & - & - \\
PVP k30 & - & - & - & - & - & - & 1 & 2 & 4 & 5 & 6 & 7 & - & - & - & - & - & - \\
Sodium starch glycolate & - & - & - & - & - & - & - & - & - & - & - & - & 2 & 4 & 6 & 8 & 10 & 12 \\
MCC & 84 & 82 & 80 & 78 & 76 & 74 & 85 & 84 & 82 & 81 & 80 & 79 & 84 & 82 & 80 & 78 & 76 & 74 \\
Magnesium Stearate & 3 & 3 & 3 & 3 & 3 & 3 & 3 & 3 & 3 & 3 & 3 & 3 & 3 & 3 & 3 & 3 & 3 & 3 \\
Talc & 2.5 & 2.5 & 2.5 & 2.5 & 2.5 & 2.5 & 2.5 & 2.5 & 2.5 & 2.5 & 2.5 & 2.5 & 2.5 & 2.5 & 2.5 & 2.5 & 2.5 & 2.5 \\
Total weight & 120 & 120 & 120 & 120 & 120 & 120 & 120 & 120 & 120 & 120 & 120 & 120 & 120 & 120 & 120 & 120 & 120 & 120 \\
\hline
\end{tabular}

Usually, between 4:00 am to noon human body releases certain hormones which not only enhances the energy and morning alertness but also raises the blood pressure which is considered as a cause for stroke. [11] This condition can be treated by employing pulsatile release systems that releases a higher concentration of drug in the morning and less amounts during the night which is why the primary aim of the present work is the in vivo evaluation of chronomodulated drug delivery of Nimodipine.

\section{MATERIALS AND METHODS}

Nimodipine was received as a gift sample from Chandra labs Hyderabad. Super disintegrants such as PVP k30, Croscarmellose sodium and MCC, magnesium stearate talc were procured from Vijlak Pharma Ltd. and Hetero drugs. $\mathrm{pH}$ sensitive polymer Eudragit S 100 were received from Chandra labs.

Preparation of Nimodipine core tablet by direct compression method

Nimodipine along with all other excipients were triturated in mortar and pestle and sieved with sieve \#60. They were weighed for the preparation of 50 tablets which are blended followed by the final addition of magnesium stearate (lubricant) and talc (glidant). This mixture was placed in cemach rotary tablet punching machine and compressed into $30 \mathrm{mg}$ tablets with $5 \mathrm{~mm}$ flat surface punches using direct compression where the total weight of the tablet was maintained at $120 \mathrm{mg}$.

Eudragit L-100 weighed at 6.5, 12.5 and $24.5 \mathrm{~g}$ was placed into $100 \mathrm{ml}$ beaker to which $50 \mathrm{ml}$ of acetone was added and mixed for 10 minutes followed by the addition of remaining $50 \mathrm{ml}$ acetone. This produces a Eudragit S100 coating solution of $12.5 \%(\mathrm{w} / \mathrm{v})$ which would release the drug at acidic $\mathrm{pH}$ 6-7.

Coating was done by using the standard coating pan, by atomizing the polymeric coating solution through the means of spray gun. The scale-up variables including pan loading, pan speed, number of spray guns, spray rate, and inlet airflow etc. were considered during the preparation process. Nimodipine tablet of approximately 50 were taken and placed in pan coater at $30 \mathrm{rpm}$ at $50^{\circ} \mathrm{C}$ temperature and coating was carried out with spraying method and dried with same.

A standard coating pan was used where, about 50 tablets of Nimodipine tablets were taken and coated with coating solution by using spray gun atomizer at 30 $\mathrm{rpm}$ and $50^{\circ} \mathrm{C}$ temperature. The scale-up variables such as pan loading, pan speed, number of spray guns, spray rate, and inlet airflow etc. were taken into consideration.

\section{In-vitro release studies}

USP dissolution apparatus II (paddle type) is used to measure the in-vitro drug release of pulsatile release capsules. The dissolution studies were carried out in $0.1 \mathrm{~N} \mathrm{HCl}$ for 2 hours, then 4 hrs in phosphate buffer of $\mathrm{pH} 6.8$ and finally 1 hour in phosphate buffer of $\mathrm{pH} 7.4$, at speed of $50 \mathrm{rpm}$ which is maintained at $37 \pm 0.5^{\circ} \mathrm{C} .5$ $\mathrm{ml}$ samples of were withdrawn at regular intervals and the same amount is replaced with buffer for every withdrawal. Samples were analyzed at $255 \mathrm{~nm}$ for Nimodipine by using UV-spectrophotometer and the amount of drug present in the sample was calculated by constructing a calibration curve.

In vivo study Pulsatile tablets of Nimodipine

Twelve New Zealand white healthy rabbits of either sex $(2-3 \mathrm{Kg})$ were selected and maintained at room temperature $25^{\circ} \mathrm{C}, \mathrm{RH} 45 \%$ and $12 \mathrm{~h}$ alternate light and dark cycle with $100 \%$ fresh air exchange in animal rooms, uninterrupted power and water supply and rabbits were fed with standard diet and water ad libitum. This protocol was approved by the institutional animal ethics committee (IAEC NO: P38/VCP/2017/24/Rabbits).

In vivo Study design [12]

Rabbits were randomly divided into two groups of 6 animals. Pulsatile Nimodipine tablets (optimized formulation F10) were administered to one group (Group A) and pure drug was administered to the other group (Group B) with an equivalent dose to animal body weight. Approximately $0.5 \mathrm{ml}$ of blood samples were withdrawn from marginal ear vein at 0 , $0.5,1,1.5,2,4,6,8,12,16,20$ and $24 \mathrm{~h}$ after dosing. Blood samples should be mixed with heparin and centrifuged at $5000 \mathrm{rpm}$ in cooling centrifuge for 5 minutes and the plasma was separated and stored at $20^{\circ} \mathrm{C}$ for further analysis.

\section{Preparation of Plasma Samples for HPLC Analysis}

Plasma samples $(0.5 \mathrm{~mL})$ were treated with $2.5 \mathrm{ml}$ of ice-cold absolute ethanol to precipitate the proteins and ethanol was transferred into a clean tube after centrifugation. The precipitate was re suspended with 1 $\mathrm{ml}$ of acetonitrile by vortexing for $1 \mathrm{~min}$. After centrifugation at 5000-6000 rpm for $10 \mathrm{~min}$, acetonitrile was added to the ethanol and the organic mixture was slightly dried by a steam of nitrogen at room temperature. Then, samples were reconstituted in 
$200 \mu 1$ of $70 \%$ of acetonitrile and $30 \%$ water for HPLC analysis.

Determination of Nimodipine in Rabbit plasma by HPLC method

In this HPLC method, samples were analyzed using Phenomenex $\mathrm{C}_{18}(250 \mathrm{~mm} \times 4.6 \mathrm{~mm}, 5.0 \mu \mathrm{m})$ column and mobile phase composed of acetonitrile: methanol in the ratio of $50: 50(\mathrm{v} / \mathrm{v})$ at a flow rate of $1 \mathrm{~mL} / \mathrm{min}$ and detected by UV detector at $237 \mathrm{~nm}$. The retention time Nimodipine (internal standard) was found to be 7.50 min respectively.

Pharmacokinetic Analysis

Various pharmacokinetic parameters such as area under the curve [AUC], elimination half-life $\left(\mathrm{t}_{1 / 2}\right)$, Volume of distribution $\left(\mathrm{V}_{\mathrm{d}}\right)$, total clearance $\left(\mathrm{Cl}_{\mathrm{T}}\right)$ and mean residence time were performed by a noncompartmental analysis and the values were expressed as the mean \pm SD. Statistical analysis was performed using one-way analysis of variance (ANOVA) followed by Tukey-Kramer multiple comparison test with $p<0.05$.

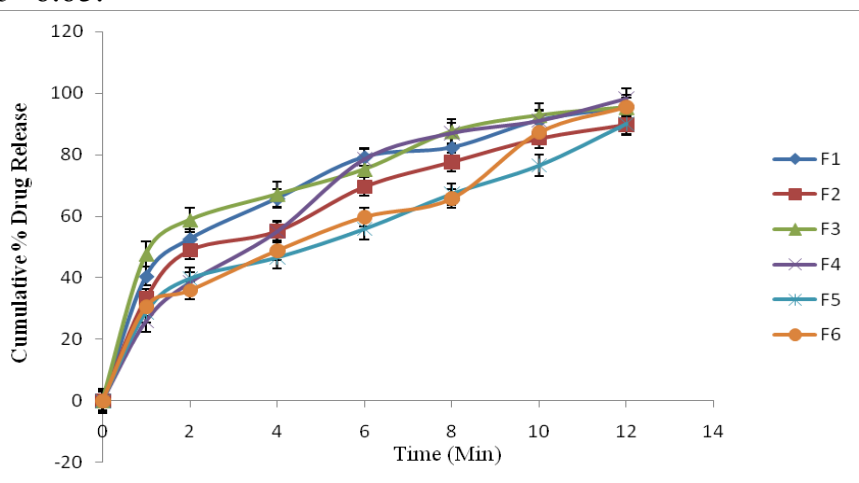

Fig. 1: In vitro Drug Release Profile for immediate release tablet of Nimodipine F1-F6

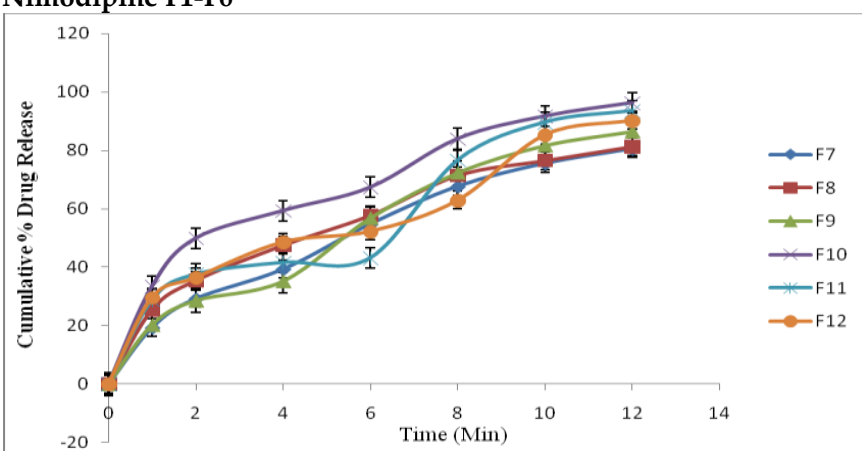

Fig. 2: In vitro Drug Release Profile for immediate release tablet of Nimodipine F7-F12

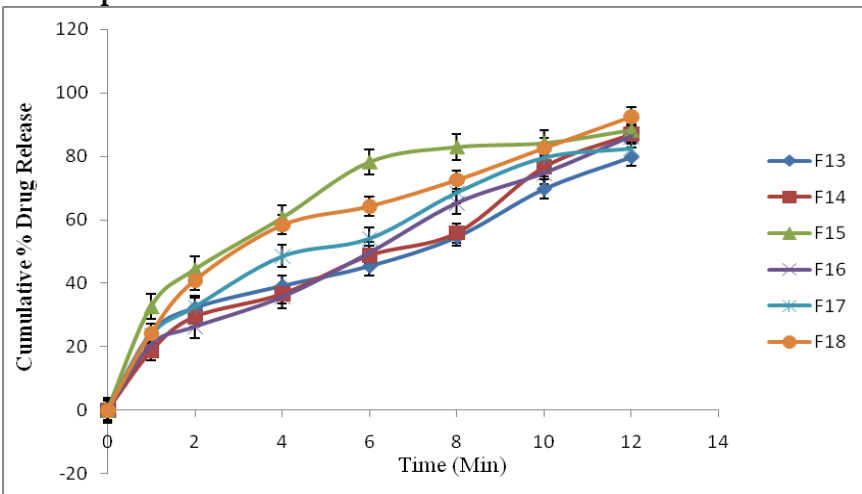

Fig 3: In vitro Drug Release Profile for immediate release tablet of Nimodipine F13-F18

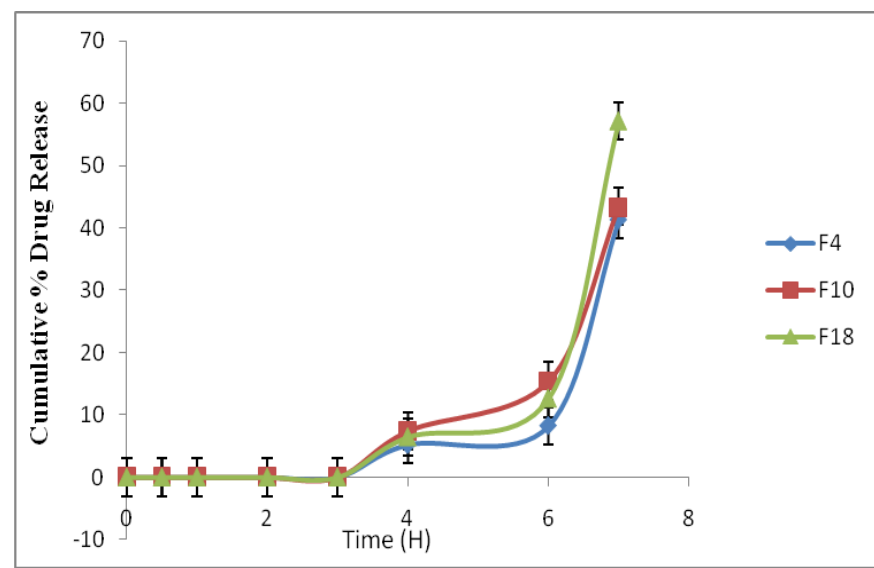

Fig. 4: In vitro Drug Release Profile for Trail 1 Prepared middle active layer of Nimodipine tablets F4, F10, F18

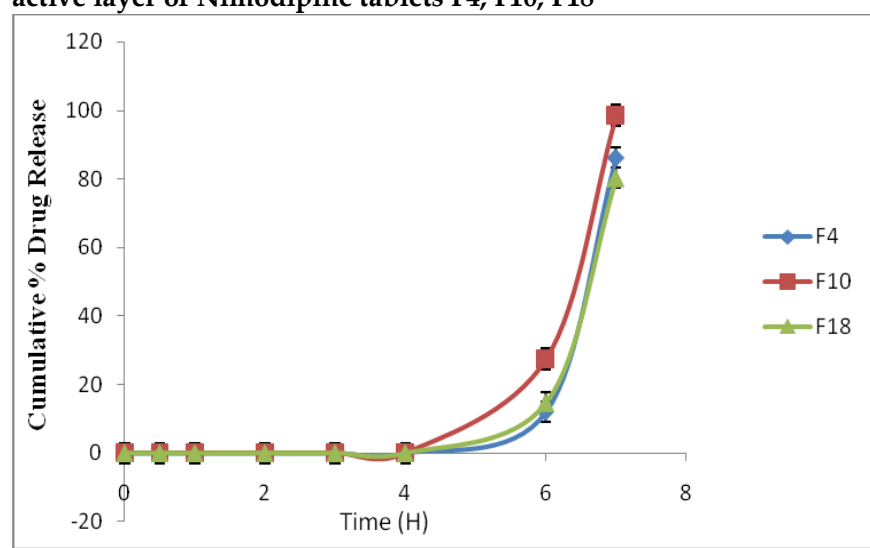

Fig. 5: In vitro Drug Release Profile for Trail 2 Prepared middle active layer of Nimodipine tablets F4, F10, F18

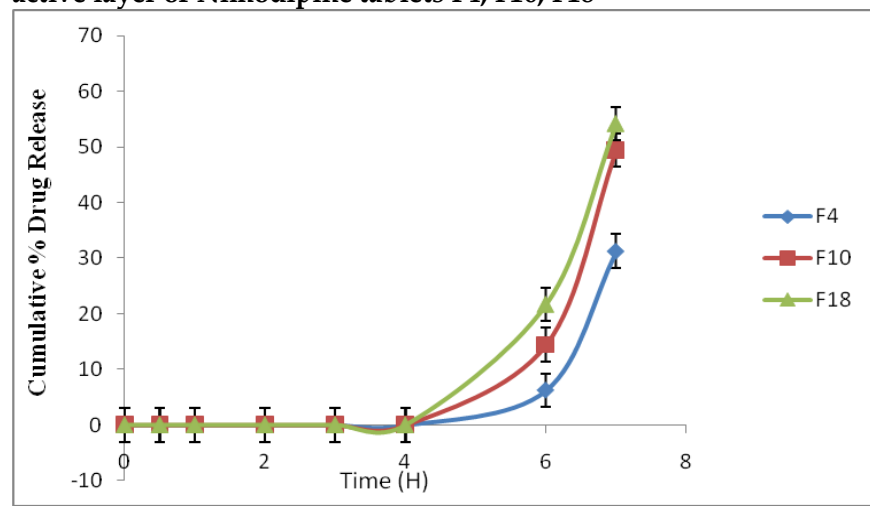

Fig. 6: In vitro Drug Release Profile for Trail 3 Prepared middle active layer of Nimodipine tablets F4, F10, F18

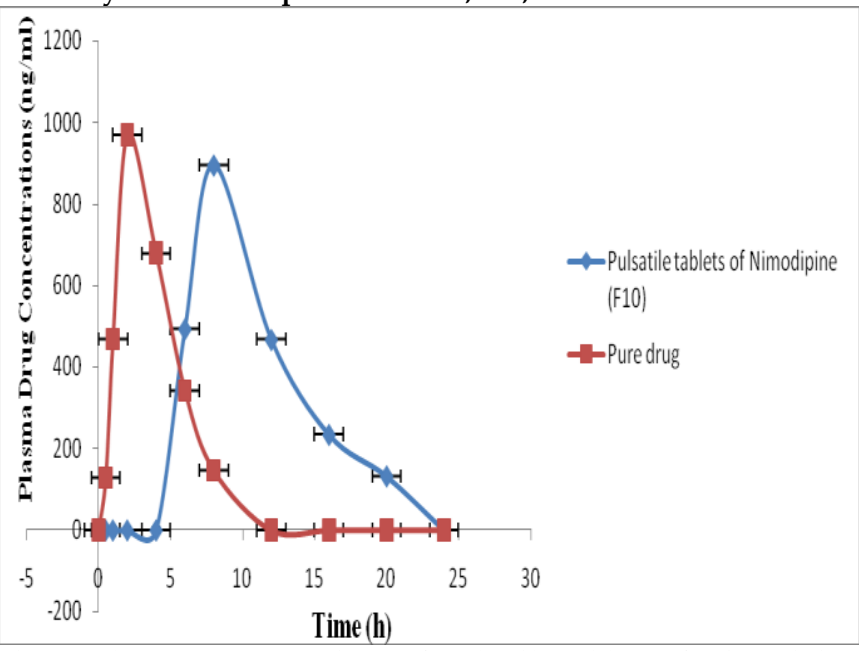

Fig. 7: Plasma Concentrations of Pulsatile tablets of Nimodipine (F10) and active drug at different time intervals (Mean $\pm S D, n=6$ ) 
Raghavender Chenna et al. / Formulation and in vivo Evaluation of Chronomodulated Drug Delivery...........

Table 2: Bulk density, Tapped density, Carr's index, Hausner's ratio, Angle of repose, $\%$ drug content

\begin{tabular}{|c|c|c|c|c|c|c|}
\hline Formulation code & Bulk density $(\mathrm{mg} / \mathrm{ml})$ & Tapped density (mg/ml) & Angle of repose & Carr's index & Hausner's ratio & $\%$ Drug content \\
\hline F1 & $0.66 \pm 0.05$ & $0.67 \pm 0.08$ & $24.34 \pm 0.44$ & $09.23 \pm 1.12$ & $1.13 \pm 0.24$ & $97.23 \pm 1.23$ \\
\hline F2 & $0.51 \pm 0.07$ & $0.68 \pm 0.06$ & $22.67 \pm 0.31$ & $08.23 \pm 1.42$ & $1.11 \pm 0.10$ & $98.04 \pm 1.03$ \\
\hline F3 & $0.55 \pm 0.06$ & $0.64 \pm 0.00$ & $26.54 \pm 0.41$ & $10.12 \pm 0.8$ & $1.13 \pm 0.20$ & $96.56 \pm 0.94$ \\
\hline F4 & $0.56 \pm 0.09$ & $0.66 \pm 0.08$ & $25.89 \pm 0.55$ & $11.34 \pm 0.6$ & $1.14 \pm 0.24$ & $98.11 \pm 0.63$ \\
\hline F5 & $0.52 \pm 0.03$ & $0.66 \pm 0.07$ & $22.56 \pm 0.0 .57$ & $12.23 \pm 0.12$ & $1.11 \pm 0.32$ & $95.23 \pm 0.81$ \\
\hline F6 & $0.51 \pm 0.08$ & $0.63 \pm 0.06$ & $25.30 \pm 0.30$ & $11.23 \pm 0.25$ & $1.12 \pm 0.30$ & $96.45 \pm 0.32$ \\
\hline F7 & $0.52 \pm 0.03$ & $0.61 \pm 0.05$ & $22.56 \pm 0.57$ & $10.34 \pm 0.31$ & $1.14 \pm 0.20$ & $95.11 \pm 1.17$ \\
\hline F8 & $0.58 \pm 0.03$ & $0.68 \pm 0.09$ & $23.67 \pm 0.60$ & $09.11 \pm 0.24$ & $1.12 \pm 0.25$ & $98.23 \pm 0.45$ \\
\hline F9 & $0.56 \pm 0.06$ & $0.67 \pm 0.03$ & $25.56 \pm 0.44$ & $09.45 \pm 1.15$ & $1.13 \pm 0.70$ & $97.13 \pm 1.17$ \\
\hline F10 & $0.66 \pm 0.05$ & $0.52 \pm 0.05$ & $21.06 \pm 0.31$ & $13.45 \pm 1.3$ & $1.09 \pm 0.20$ & $96.23 \pm 0.49$ \\
\hline F11 & $0.54 \pm 0.09$ & $0.58 \pm 0.07$ & $22.34 \pm 0.37$ & $14.23 \pm 1.5$ & $1.13 \pm 0.16$ & $98.97 \pm 0.95$ \\
\hline F12 & $0.57 \pm 0.06$ & $0.64 \pm 0.01$ & $25.99 \pm 0.70$ & $11.34 \pm 1.25$ & $1.12 \pm 0.12$ & $98.45 \pm 0.35$ \\
\hline F13 & $0.57 \pm 0.07$ & $0.68 \pm 0.05$ & $23.14 \pm 0.50$ & $09.67 \pm 1.55$ & $1.09 \pm 0.14$ & $99.85 \pm 0.24$ \\
\hline F14 & $0.59 \pm 0.05$ & $0.59 \pm 0.08$ & $22.09 \pm 0.57$ & $10.23 \pm 1.55$ & $1.14 \pm 0.15$ & $99.18 \pm 0.13$ \\
\hline F15 & $0.57 \pm 0.08$ & $0.66 \pm 0.04$ & $24.78 \pm 0.77$ & $10.45 \pm 1.5$ & $1.15 \pm 0.15$ & $99.25 \pm 1.21$ \\
\hline F16 & $0.58 \pm 0.00$ & $0.64 \pm 0.06$ & $23.45 \pm 0.80$ & $09.68 \pm 1.3$ & $1.18 \pm 0.18$ & $97.45 \pm 1.30$ \\
\hline F17 & $0.51 \pm 0.04$ & $0.68 \pm 0.07$ & $21.89 \pm 0.86$ & $09.47 \pm 1.09$ & $1.12 \pm 0.15$ & $99.94 \pm 1.31$ \\
\hline F18 & $0.54 \pm 0.06$ & $0.61 \pm 0.09$ & $23.05 \pm 0.75$ & $14.99 \pm 1.20$ & $1.14 \pm 0.15$ & $98.56 \pm 1.36$ \\
\hline
\end{tabular}

Above parameters are communicated as Average \pm Standard Deviation; $(\mathrm{n}=3)$

Table 3: Comparison of PK parameters of pulsatile tablets of Nimodipine (F10) and Pure Drug

\begin{tabular}{ccc}
\hline Parameters & $\begin{array}{c}\text { Pulsatile tablets of } \\
\text { Nimodipine (F10) }\end{array}$ & Pure Drug \\
\hline $\mathbf{C}_{\max }(\mathbf{n g} / \mathbf{m l})$ & $895.20 \pm 7.05$ & $968.75 \pm 8.78$ \\
AUC $_{0-\mathrm{t}}(\mathbf{n g ~ h} / \mathbf{m l})$ & $3940.30 \pm 4.11$ & $3240.52 \pm 4.01$ \\
AUC $_{0-\infty}(\mathbf{n g ~ h} / \mathbf{m l})$ & $4412.97 \pm 5.14$ & $3842.78 \pm 2.02$ \\
$\mathbf{T}_{\max }(\mathbf{h})$ & $7.99 \pm 0.12$ & $2.01 \pm 0.14$ \\
$\mathbf{t}_{1 / 2}(\mathbf{h})$ & $10.15 \pm 0.05$ & $4.50 \pm 0.014$ \\
MRT $_{\mathbf{h}}$ & $10.28 \pm 4.85$ & $4.014 \pm 2.34$ \\
\hline
\end{tabular}

\section{RESULTS AND DISCUSSION}

Nimodipine pulsatile release tablets were made by incorporating various types of super disintegrants such as PVP k30, sodium starch glycolate and croscarmellose at varying concentrations. Ideal formulations (F4, F10 and F18) were selected for evaluating drug dissolution studies. The three formulations were coated with 6.5 , 12.5 and $24.5 \mathrm{~g}$ coating solutions in trail 1,2 and 3 respectively where trail 2 presented satisfactory release. $5 \%$ PVP k30 polymer showed better drug release when compared to Croscarmellose and sodium starch glycolate. Formulations that contained 8\% croscarmellose presented a maximum drug release of $84.24 \%$ after seventh hour where formulations with $5 \%$ PVP presented $98.42 \%$ drug release. A lag time of 6 hrs was achieved with Eudragit S-100. F10 was chosen as the best formulation based on the drug release pattern. Dissolution profiles were showed in Figure 1-6.

The pulsatile release of formulated Nimodipine tablets was studied in rabbits after oral administration. In-vivo evaluation studies were performed based on the uniform and reliable results of in-vitro drug release studies. Various pharmacokinetic parameters were compared to obtain mean plasma drug concentration curve versus time. From each animal's drug plasma profile $C_{\max }$ and $T_{\max }$ of the three formulations (Table 3) were obtained. Animals that received Nimodipine pulsatile tablets have a $\mathrm{AUC}_{0-\mathrm{t}}$ of $3940.30 \pm 4.12$ $\mathrm{ng} / \mathrm{ml} / \mathrm{hr}$ and those which received pure drug has an $\mathrm{AUC}_{0-24}$ of $3240.52 \pm 4.02 \mathrm{ng} / \mathrm{ml} / \mathrm{hr}$. In vivo release of pulsatile tablets was based on the mean residence time where an increase in the MRT from 4.014 to $10.28 \mathrm{~h}$ was a result of alteration in drug release and elimination. The average $T_{\max }$ for pure drug Nimodipine was found to be $2.00 \pm 0.14 \mathrm{~h}$ and that of pulsatile drug was $8.00 \pm$ $0.12 \mathrm{~h}$. Pure drug presented a low $\mathrm{T}_{\max }$ than pulsatile formulation indicating a rapid absorption. Table 3 reveals a lag time of 3 hrs for pure and pulsatile Nimodipine before finally showing maximum concentration $\left(\mathrm{C}_{\max }\right)$ at 8 hours that correlated with the in-vitro drug release of 8 hours and the statistically difference between the groups was significant at $p \leq$ 0.05 .

Nimodipine pulsatile release tablets were prepared based on the chronopharmacology of hypertension as $120 \mathrm{mg}$ tablet. From the formulations prepared, F10 showed a beneficial lag time of 7 hours and drug release within 15 minutes which was found to be used in treating morning stroke in hypertensive patients.

\section{REFERENCES}

1. Sajan J, Cinu TA, Chacko AJ, Litty J, Jaseeda T Chronotherapeutics and Chronotherapeutical drug delivery system. Tro. J. Pharma Res. 2009; 8(5): 467-475.

2. Traynor K, Newton DW, Hrushesky JM, Reiter RJ. A Pharmacist's Primer on Chronotherapeutics American Pharmacy. 1992; 32 (2): 261-269.

3. Shanmugan P, Bandameedi R. Chronotherapeutics Drug delivery system. J Drug Metab Toxicol. 2015; 2(1): 204-15.

4. Parmar RD, Parikh RK, Vidyasagar G, Patel DV, Patel CJ, Patel BD. Pulsatile drug delivery systems: an overview. Int J pharm sci nanotech. 2009; 2(3):605-614.

5. Korner A, Larsson A, Andersson A, Piculelle L. Swelling and polymer erosion for polyethylene oxide tablets of different molecular weights polydispersities. J Pharm Sci. 2009; 99:1225-1238.

6. Lin HL, Lin SY, Lin YK, Ho HO, Lo YW, Sheu MT.. Release characteristics and in vitro-in vivo correlation of pulsatile pattern for a pulsatile drug delivery system activated by membrane rupture via osmotic pressure and swelling. Europ J Pharm Biopharm. 2008; 70:289-301.

7. Mc Conville J, Ross A, Florence A, Stevens H. Erosion characteristics of an erodible tablet incorporated in time delayed capsule device. Drug Dev. Ind. Pharm. 2005; 31:3542.

8. Minami J, Kawano Y, Makino Y, Matsuoka H, Takishita, S. Effects of cilnidipine, a novel dihydropyridine calcium antagonist, on autonomic function, ambulatory blood 
Raghavender Chenna et al. / Formulation and in vivo Evaluation of Chronomodulated Drug Delivery

pressure and heart rate in patients with essential hypertension". British J Clin Pharmacol. 2017; 50 (6): 615-620.

9. Shetty R, Vivek G, Naha K, Tumkur A, Raj A, Bairy KL. Excellent Tolerance to Cilnidipine in Hypertensives with Amlodipine - Induced Edema. North American J Med Sci. 2017; 5 (1): 47-50.

10. Matsui Y, Eguchi K, Shibasaki S, Ishikawa J, Hoshide S, Pickering TG, Shimada K, Kario K. Effect of doxazosin on the left ventricular structure and function in morning hypertensive patients: the Japan Morning Surge 1 study. J
Hypertens. 2008; 26:1463-1471.

11. Marfella R, Siniscalchi M, Nappo F, Gualdiero P, Esposito K, Sasso FC, Cacciapuoti F, Di Filippo C, Rossi F, D'Amico M, Giugliano D. Regression of carotid atherosclerosis by control of morning blood pressure peak in newly diagnosed hypertensive patients. Am J Hypertens. 2005; 18:308-318.

12. Raghavendra K, Koland M. An In-Vivo Evaluation of Chronotherapeutical Drug Delivery System for the Treatment of Hypertension, Saudi Journal of Medical and Pharmaceutical Sciences. 2017; 3(6B):643-647.

HOW TO CITE THIS ARTICLE: Chenna R, Padmanabha Reddy Y. Formulation and in vivo Evaluation of Chronomodulated Drug Delivery of Nimodipine. Int. J. Pharm. Sci. Drug Res. 2019; 11(6): 325-329. DOI: 10.25004/IJPSDR.2019.110607 